\title{
Government regulation and enterprise decision in China remanufacturing industry: evidence from evolutionary game theory
}

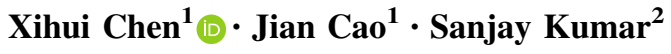 \\ ${ }^{1}$ School of Management, Zhejiang University of Technology, Hangzhou 310023, China \\ ${ }^{2}$ College of Business, Valparaiso University, Valparaiso 46383, USA
}

Received: 9 August 2020/Revised: 18 September 2020/Accepted: 13 October 2020/Published online: 1 November 2020

(c) The Joint Center on Global Change and Earth System Science of the University of Maryland and Beijing Normal University 2020

\begin{abstract}
Currently, the large-scale industrial production has made mountains of scrapped products and inevitably exerts irreversible damage to the nature resource and environment. Under this real situation, remanufacturing industry is able to provide a new path for government and enterprises to deal with the scrapped products and find the new growth point of ecological economy. So, the problem that how to push forward the development of remanufacturing via the regulations of government has become the focus to the scholars and practitioners of enterprises. In this paper, the evolutionary game model was established in order to analyze the optimal strategies for both the government and the enterprises. Based on the obtained results from evolutionary game model, it shows that when the revenues gotten from supervision activities surpass the costs, government will supervise enterprises' production pattern positively. Meanwhile, if the profits earned by polluted production are higher than it in remanufacturing production, enterprises will keep their patter of production, although they may face the penalties of government. Then, a case study based on the long-term perspective was introduced in order to verify the rationality of the game model in math. The result of this paper shows that the regulation of government will exert the significant influences to firms' decision about remanufacturing. During the different periods of remanufacturing industry development, government regulations will make different influences.
\end{abstract}

Keywords Government regulation · Green decision · Evolutionary game $\cdot$ Game theory $\cdot$ Circular economy

Xihui Chen

jerrychen0526@foxmail.com

\section{Introduction}

Remanufacturing is able to bring environmental and economic benefits to every country. Regarded as the environmentally friendly industry, remanufacturing now has gradually received intense attentions from the researchers and government agencies. In response to the resource shortages, excessive energy consumption as well as the environmental degradation, remanufacturing provides a viable option for managing the increase in the number of scrapped products worldwide (Kelly et al. 2017; Cao et al. 2020). Through a series of industrial procedures that may include inspection, dismantling, repair, and testing, remanufacturing can restore the used product to the same capacity as the new products (Gagnon and Morgan 2014; Sofia et al. 2017). Comparing with the usage of the "new" components for production, remanufactured products can also reduce electricity consumption by about $60 \%$, metal materials by $70 \%$, and alleviate the air pollutant emissions by about $80 \%$ (Chang et al. 2015; Kasman and Duman 2015).

The policies of Swap the Old for Remanufacturing and Pilot Remanufacturing Enterprises, introduced in 2013, had encouraged and provided impetus to firms enter into remanufacturing industry. These policies are largely responsible for the current growth paces of remanufacturing in China. The government selected a set of Pilot Remanufacturing Enterprises and supported them with initial capital and expertise in this emerging field (MIIT 2014). These pilot companies were tasked with pioneering remanufacturing activities. Swap the Old for Remanufacturing initiative provides government funded subsidies to the pilot enterprises. Our research team investigated these pilot enterprises, and the remanufacturing industry and 
production line in China are shown in Fig. 1. The policy encourages such enterprise enhancing the recovery scale of end-of-life (EOL) products (Tian and Chen 2014; Wei et al. 2015). Policies and practices to advance remanufacturing industry have been the focus of researchers and scholars of circular economy, policy makers, and the practitioners of remanufacturing enterprises, as well as the potential customers.

Hence, the governmental measures like policies above play an important role in the development of remanufacturing industry. Meanwhile, remanufacturing industry in China has undertaken about 2 decades, so how about the evolution progress of this emerging industry in China? What measures could the double participants (government and enterprise) adopt in different periods of remanufacturing industry's development? Thus, deriving from these problems, we regard government regulation and enterprise decision as the research target. In this paper, we use evolutionary game models to analyze the relationship between the government and the manufacturing enterprises and research on their decisions to prompt remanufacturing industry. Compared with the traditional game theory, evolutionary game model can depict the changes and evolution progress of decisions of participants in the model. Participants here can adjust their preferable strategies according to the development of China's remanufacturing industry, which is more closing to the practical operation situations in China. Based on the replicator dynamics equations, we can obtain the evolutionary stable strategies (ESS), which are used to get preferable strategies for the participants (government and enterprise) in the game model. In order to support the results of evolutionary game model, the practical case study is also provided in the paper to prove the evolution progress of China remanufacturing industry.

The rest of the paper is organized as follows: After the introduction, in Sect. 2, we provide a brief literature review. In Sect. 3, an evolutionary game model between the government and firms is developed. An practical case study based on our field investigations is introduced in Sect. 4. Finally, in conclusion, Sect. 5 outlines the highlights of this paper, gives several practical
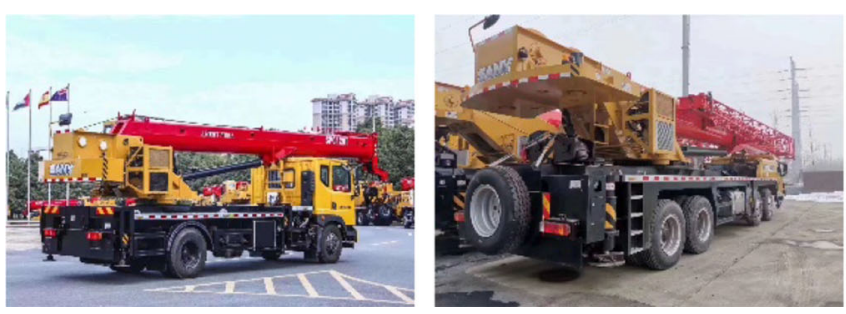

Fig. 1 Remanufacturing industry and production line in China recommendations, and discusses future prospects of Chinese remanufacturing industry.

\section{Literature review}

Regarded as the new research field of circular economy and renewable business, remanufacturing has attracted the attentions of academic scholars and practitioners of firms. During the recent years, a growing number of papers related to remanufacturing have been published. By the observations and analysis of the previous papers, the research methods in the field of remanufacturing are also diversified. Hence, in this section, the literature review was analyzed from three parts. Finally, comparing with the previous literature, we summarized the contributions our research did to highlight the innovating aspects of this paper.

\subsection{Remanufacturing supply chain management}

Research on the remanufacturing supply chain derived from the paper published via Savaskan et al. (2004) utilized the Stackelberg game theory to calculate the recovering rates of the end-of-life products. Since then, study on remanufacturing has become the hot research topic in circular economy. Rubio and Corominas (2008) carried out their research based on Savaskan et al. (2004) to study and analyze the optimal decisions of the manufacturing-remanufacturing in the lean production environment. Afterward, $\mathrm{Wu}$ (2012) established the two-echelon supply chain model in remanufacturing industry to analyze the effects of price and service competition in new/remanufactured products. Taking the uncertainty into consideration, Chen et al. (2015) adopted a two-stage stochastic supply chain design model which incorporated uncertainty to analyze the cannibalization in the OEM or remanufactured production markets. The results via their working show that primary cost in each product was crucial to the cannibalization phenomenon.

A growing number of papers focusing on this emerging industrial chain have been published during the past 5 years. For instance, Giovanni (2016) assumed a non-
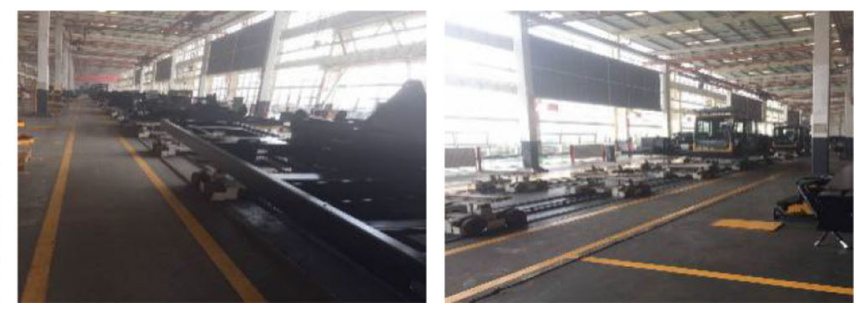
incentive scenario to study the profit-sharing contracts between the manufacturer and retailer, where the former is the leader and the other is seen as the follower in the game model. Jin et al. (2017) have explored mobile phone remanufacturing using a game-based model. They analyze the impact of third-party remanufacturing. Their model reveals that entry of a third-party remanufacturer is beneficial for a high "capability" OEM remanufacturer. Recently, taking the process innovation into the consideration, Reimann et al. (2019) tried to take process innovation as the variable into the math model of remanufacturing supply chain and analyzed its effects into this sustainable supply chain.

\subsection{Evolutionary game theory in sustainable industry}

As for the new and hot research topic now, there are many papers which adopted the diverse research methods and theories to research remanufacturing. Comparing with the traditional game theory, evolutionary game theory is welcomed by more and more researchers, due to its characteristics of limited rationality which is more closer to the real operation situations in remanufacturing supply chain. Let's take a instance, in the reverse logistics, Dong and Song (2012) proposed an evolutionary game model deriving from the duplication dynamics, which provided references to how suppliers choose their optimal decisions. Moreover, Ji et al (2015) focused on green purchasing relationships and analyzed dynamic operations and strategic changes for a long-term green purchasing relationship between the suppliers and manufacturers. Based on an evolutionary game model, a replicator dynamic system was formulated, which helped study different evolutionary stable strategies of various stakeholders in green supply chains in diverse periods.

Chen and $\mathrm{Hu}$ (2018) utilized evolutionary game theory to obtain the optimal decision strategies of the manufacturers and the government under the background of the carbon taxation and governmental subsidies. Furthermore, corporate social responsibility (CSR) is a hot norm in the field of ecology and environment, and Maryam et al. (2019) deemed combing of the CSR with evolutionary game theory would get the new findings. Hence, in their paper, evolutionary game models were established to analyze the pricing strategy and long-term behavior of manufacturers which have the CSR in the daily productions. Later, Xu et al (2020) focused on governmental regulations with green supply chain decisions to explore the relationship between the enterprises and government, which also provided implication to the establishment of the game model in this paper.

\subsection{Practical case studies on remanufacturing industry}

Case study is another common and practical method in the researches of circular economy. Both the scholars in China or the countries have utilized this method to study remanufacturing and gotten obvious achievements. In the developing country "Brazil," Saavedra et al. (2013) applied a case to show that in Brazil, the cooperation between the OEM firms with other independent companies can improve the profits for the both collaborators. Later, turning the research direction of case study to developed countries, here are also some distinctive findings. Other scholars such as Rafiei et al. (2015), they regarded electronic mechanical as the research objective and utilized the case studies to survey the remanufactured electronic mills in Canada to analyze the dynamic safety stocks of the reman-productions. Researchers are already aware of the environmental benefits brought via remanufacturing industry; hence, Liu et al. (2016) selected the remanufactured cylinder of automobiles as practical case to investigate environmental benefits in China. Peters (2016) put forward to evaluate life cycle assessment (LCA) via the case studies. Hence, one case study of remanufactured office equipment like folder inserter was presented to illustrate the LCA of remanufactured production in European developed countries.

Eco-efficiency is an index to evaluate the environmental benefits; therefore, case study combing with Eco-efficiency is a meaningful research direction for scholars. So, Afrinaldi et al. (2017) utilized the case study of remanufactured cylinder block to assess this index. Krystofik et al. (2018) took Davies Office, Inc., as the research object to form the case which displayed that in the USA, the factors which influence the economic and the environmental impacts of remanufacturing office equipment are multidimensional. Disposed engines now are the major sources for remanufacturing in China, and Shi et al. (2019) investigated a real case study on diesel engines to evaluate greenhouse gas (GHG) emission situation in northeast of China.

By the reviewing of the literature above, we get the implications to carry out our research in the paper. Then we want to present the decision making between the government and enterprises clearly and outline the evolution path of remanufacturing industry in China. In this paper, we adopted the evolutionary game theory and case study together to launch the research as introduced in Sect. 3. Despite the prior researches and literature, remanufacturing acted as an emerging and hot research topic, and it needs more various ways to study it.

Based on the literature review above, our paper contributes to the literature in the aspects as follows: (1) There are few papers which utilize the game theory to research 
the decision making between government and enterprise with the limited rationality. Hence, our research provided the macro-decision making from a long-term perspective. In our game model, the decision will adjust according to the different periods of remanufacturing development. (2) Though there are many papers related to case study on remanufacturing industry, however, there are lack of case studies to analyze the evolution path between government and enterprise. Thus, in our paper, we used the case study via our field investigations to prove and verify the results we obtained from evolutionary game model. (3) In order to promote the development of remanufacturing industry, we also put forward the management insights and policy suggestions based on our research results which is in line with China remanufacturing practical situations and can provide implications to other developing nations.

\section{Evolutionary game theoretical model}

In this section, we first introduce the participants in the game model and basic assumptions of the evolutionary game model. According to the model hypotheses, the evolutionary game payoff matrix between the government and the manufacturing enterprises was established, and then, the actual meanings of each parameter in the model were explained in details. After solving the model, the potential stable points of the evolutionary game model were obtained. Later, the Jacobian matrix judgment method was utilized to analyze the stability of the obtained equilibrium points. Finally, according to the obtained stability points from the evolutionary game, the schematic diagram of the replication dynamics is given afterward.

\subsection{Problem description and model assumptions}

In this evolutionary game theoretical model, there are two game players: One is the manufacturing company, and the other is an administrative government. At the same time, both the government and the enterprise as the main players of the game are based on the assumption of "Rational People"; that is, both participants in the game seek to maximize their own revenuer or benefits (Smith 2012; Chen et al. 2020). In the evolutionary game model, both parties will make decisions at the same time. For manufacturing companies, there are two types of decisionmaking behaviors: regular (polluted) production and remanufacturing. The game strategy set can be described as: (remanufacturing, non-remanufacturing). Another participant in the game model, the local government, which plays the role of administrative supervision, also has two decision-making behaviors: administrative supervision and non-supervision. Under the same strategy set, it can be described as: (supervision, non-supervision). Hence, the gaming relationship between the government and enterprise is presented in Fig. 2 (Table 1).

Meanwhile, the evolutionary game focused on the decision-making behaviors between different groups. Therefore, it can be assumed that in the game process: The proportion of manufacturing enterprises choosing regular production is $x$, and then, the proportion of enterprises choosing remanufacturing production is $(1-x)$. As far as local governments are concerned, the proportion that selects supervision is $y$, while the proportion that chooses

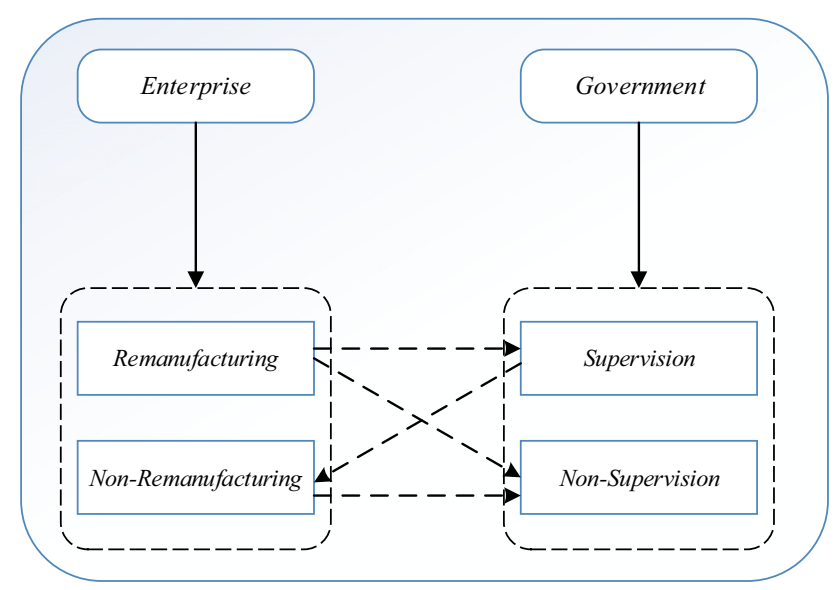

Fig. 2 Relationship between government and enterprise in the evolutionary game model

Table 1 Notation and description

\begin{tabular}{ll}
\hline Notation & Description \\
\hline$V$ & The environmental benefits via remanufacturing \\
$C$ & Cost and expense of supervision via government \\
$S$ & Subsidies on remanufacturing production via government \\
$F$ & Fines on polluted production on the regular production \\
$D$ & Pollution treatment fees via enterprises \\
$\pi_{M}$ & Revenue of regular production via enterprises \\
$\pi_{R}$ & Revenue of remanufacturing via enterprises \\
\hline
\end{tabular}

Table 2 Payoff matrix for government and enterprise

\begin{tabular}{lll}
\hline & Enterprise & \\
\cline { 2 - 3 } & Remanufacturing & Non-remanufacturing \\
\hline Government & & \\
Supervision & $\left(V-C-S, \pi_{R}+S\right)$ & $\left(F-V-C, \pi_{M}-F-D\right)$ \\
Non-supervision & $\left(V, \pi_{R}\right)$ & $\left(-V-D, \pi_{M}\right)$ \\
\hline
\end{tabular}


non-supervision is $(1-y)$. Hence, we can get the payoff matrix between the government and enterprises in Table 2 :

\subsection{Model calculations and stability analysis}

For the government, the expected revenue of supervision strategy is:

$U_{E Y}=x\left(\pi_{M}+S\right)+(1-x) \pi_{R}$

Meanwhile, as for the government, expected benefit of non-supervision strategy can be depicted as:

$U_{G N}=y V+(1-y)(-V-D)$

Hence, we can get the government's average revenue function presented as:

$\bar{U}_{G}=x U_{G Y}+(1-x) U_{G N}$

From Eqs. (1) to (3), using the replicator dynamics system in Samuelson (1997), Smith (2012) and Xiao et al. (2018), the equation for government is expressed as:

$F(x)=\frac{\mathrm{d} x}{\mathrm{~d} t}=x\left(U_{M Y}-\bar{U}_{M}\right)$

Substituting Eqs. (1) to (3) into replicator dynamics function, it can be obtained that:
Substituting Eqs. (5) to (7) into replicator dynamics function of enterprise Eqs. (8), it would be transformed to the function like:

$F(y)=\frac{\mathrm{d} y}{\mathrm{~d} t}=y(1-y)\left[(F+S+D) x-\left(\pi_{M}-\pi_{R}\right)\right]$

Let Eqs. (8) $=0$, we can have the solutions as: $y_{1}^{*}=0 ; y_{2}^{*}=1 ; x_{0}=\frac{\pi_{M}-\pi_{R}}{F+S+D}$.

Thus, four potential stable evolutionary strategies (ESS) with different combinations of the $x \in\{0,1\}$ and $y \in\{0,1\}$ can be obtained. More specifically, the combinations for $(x$, $y$ ) for these strategies could be: $O(0,0) ; A(1,0) ; B(0,1)$; $C(1,1)$ as well as $D\left(\frac{\pi_{M}-\pi_{R}}{F+S+D}, \frac{F-C+D}{F+S+D}\right)$.

Using methods outlined by Milton Friedman (Ji et al. 2015; Chen and Hu 2018; Maryam et al. 2019), the Jacobian matrix is used for stability analysis by satisfying the conditions: $\operatorname{det} J>0$ and $\operatorname{tr} J<0$.

Jacobian $=\left[\begin{array}{ll}\frac{\partial F(x)}{\partial x} & \frac{\partial F(x)}{\partial y} \\ \frac{\partial F(y)}{\partial x} & \frac{\partial F(y)}{\partial y}\end{array}\right]$

Substituting the values into the Jacobian matrix, it can be transformed to:

Jacobian $=\left[\begin{array}{ll}(1-2 x)[(F+D-C)-(F+S+D) y] & -x(1-x)(F+S+D) \\ y(1-y)(F+S+D) & (1-2 y) \cdot\left[\left(\pi_{R}-\pi_{M}\right)+x(F+S+D)\right]\end{array}\right]$

$F(x)=\frac{d x}{d t}=x(1-x)[(F-C+D)-(F+D+S) y]$

Let Eqs. (4) $=0$, we can have the solutions as: $x_{1}^{*}=0 ; x_{2}^{*}=1 ; y_{0}=\frac{(F-C+D)}{F+S+D}$.

Turn the attentions to enterprise, the expected profits of regular production is:

$U_{E Y}=x\left(\pi_{R}+S\right)+(1-x) \pi_{R}$

Similarly, the expected profit of enterprise's remanufacturing production is:

$U_{E N}=x\left(\pi_{M}-F-D\right)+(1-x) \pi_{M}$

Thus, we can get the enterprise's average revenue function presented as:

$\bar{U}_{E}=y U_{E Y}+(1-y) U_{E N}$

From Eqs. (5) to (7), the replicator dynamics function of enterprises is shown as:

$F(y)=\frac{\mathrm{d} y}{\mathrm{~d} t}=y\left(U_{R Y}-\bar{U}_{R}\right)$
Using the Jacobian matrix, we can analyze the stability of four potential points, and the stability analysis is shown in Table 3. According to the stability analysis, we can get the related propositions as follows.

From the stability analysis we did in Table 3 , it is convenient for us to observe the preferable strategies for the two participants in the evolutionary game model. When the remanufacturing enters into diverse stages, what are the preferable decisions for the enterprises and the government. Meanwhile, the prerequisites of the participants adopting different strategies are also introduced after the propositions. By the propositions we obtained as follows, we can understand in which scenarios the government will supervise the enterprises and how firms select their strategies. The threshold conditions for each party's behavior are analyzed in Table 3 .

According to Table 3 , the stability of each equilibrium point can be analyzed and the following relevant Propositions can be obtained successively. There are eight scenarios with the various prerequisites. Based on the different scenarios, we can discuss the diverse decision situations 
Table 3 Stability analysis of equilibrium point in evolutionary game

\begin{tabular}{|c|c|c|c|c|c|}
\hline Scenario & Conditions & Point & $\operatorname{det} J$ & $t r J$ & Stability \\
\hline \multirow[t]{5}{*}{ Scenario $I$} & $F+D<C$ & $(0,0)$ & + & - & ESS \\
\hline & $\pi_{R}<\pi_{M}$ & & & & \\
\hline & & $(1,0)$ & + & + & Unstable point \\
\hline & & $(0,1)$ & - & \pm & Saddle point \\
\hline & & $(1,1)$ & \pm & \pm & Uncertain point \\
\hline \multirow[t]{5}{*}{ Scenario $I I$} & $F+D>C$ & $(0,0)$ & - & \pm & Saddle point \\
\hline & $\pi_{R}<\pi_{M}$ & & & & \\
\hline & & $(1,0)$ & \pm & \pm & Uncertain point \\
\hline & & $(0,1)$ & - & \pm & Saddle point \\
\hline & & $(1,1)$ & \pm & \pm & Uncertain point \\
\hline \multirow[t]{5}{*}{ Scenario III } & $F+D<C$ & $(0,0)$ & - & \pm & Saddle point \\
\hline & $\pi_{R}>\pi_{M}$ & & & & \\
\hline & & $(1,0)$ & + & + & Unstable point \\
\hline & & $(0,1)$ & + & - & ESS \\
\hline & & $(1,1)$ & - & \pm & Saddle point \\
\hline \multirow[t]{5}{*}{ Scenario $I V$} & $F+D>C$ & $(0,0)$ & - & \pm & Saddle point \\
\hline & $\pi_{R}>\pi_{M}$ & & & & \\
\hline & & $(1,0)$ & + & + & Unstable point \\
\hline & & $(0,1)$ & + & - & ESS \\
\hline & & $(1,1)$ & - & \pm & Saddle point \\
\hline \multirow[t]{5}{*}{ Scenario $V$} & $F+D>C$ & $(0,0)$ & - & \pm & Saddle point \\
\hline & $\pi_{R}+S<\pi_{M}-F-D$ & & & & \\
\hline & & $(1,0)$ & + & - & ESS \\
\hline & & $(0,1)$ & - & \pm & Saddle point \\
\hline & & $(1,1)$ & + & + & Unstable point \\
\hline \multirow[t]{5}{*}{ Scenario $V I$} & $F+D>C$ & $(0,0)$ & \pm & \pm & Uncertain point \\
\hline & $\pi_{R}+S>\pi_{M}-F-D$ & & & & \\
\hline & & $(1,0)$ & - & \pm & Saddle point \\
\hline & & $(0,1)$ & \pm & \pm & Uncertain point \\
\hline & & $(1,1)$ & - & \pm & Saddle point \\
\hline \multirow[t]{5}{*}{ Scenario $V I I$} & $F+D<C$ & $(0,0)$ & + & - & ESS \\
\hline & $\pi_{R}+S<\pi_{M}-F-D$ & & & & \\
\hline & & $(1,0)$ & - & \pm & Saddle point \\
\hline & & $(0,1)$ & - & \pm & Saddle point \\
\hline & & $(1,1)$ & + & + & Unstable point \\
\hline \multirow[t]{5}{*}{ Scenario VIII } & $F+D<C$ & $(0,0)$ & \pm & \pm & Uncertain point \\
\hline & $\pi_{R}+S>\pi_{M}-F-D$ & & & & \\
\hline & & $(1,0)$ & + & + & Unstable point \\
\hline & & $(0,1)$ & \pm & \pm & Uncertain point \\
\hline & & $(1,1)$ & - & \pm & Saddle point \\
\hline
\end{tabular}

which the participants in the evolutionary game model will face and how they select their preferable strategies. When we obtain the ESS points, the preferable strategies are presented directly.

Proposition 1 At this time, two cases in the evolution game system are based on $(0,0)$ as the ESS points, when conditions $F+D<C$ and $\pi_{R}<\pi_{M}$, or $F+D<C$ and
$\pi_{R}+S<\pi_{M}-F-D$ are satisfied. ESS for the government and enterprise is regarded as (non-supervision, nonremanufacturing).

Specifically, it means when the profits of enterprises earning by the regular production are higher than it got in remanufacturing, the enterprises will continue to make the production with pollution, although they may face the 
penalty from the government. By contrast, when the supervision cost of government is higher than the sum of penalty fees and pollution treatment costs, the government is supposed to lose the enthusiasm to supervise enterprises' production behaviors.

Proposition 2 When both the conditions: $F+D>C$, $\pi_{R}+S<\pi_{M}-F-D$ are satisfied, therefore, in this scenario, the ESS for the government and enterprise is (supervision, non-remanufacturing).

This prerequisite denoted that if the government's penalty fees on the pollution combing with the pollution treatment cost are higher than the supervision expense, at that time, the government is expected to take active supervisions on the enterprises. At the same time, government can reduce it cost in supervisions, encouraging it to adopt the positive measures. Meanwhile, the profits of enterprises earning by the regular production are higher than it got in remanufacturing, leading the firms to continue their production ways, although it may face the penalties by government.

Proposition 3 When both the conditions: $F+D<C$ and $\pi_{R}>\pi_{M}$ or $F+D>C$ and $\pi_{R}>\pi_{M}$ are both satisfied, therefore, in these scenarios, ESS for the government and enterprise is regarded as (non-supervision, remanufacturing).

When both the manufacturing enterprises and the government adopt this decision set, it means remanufacturing in China has stepped into the mature stage. In this period, due to the more profits brought via remanufacturing production, the enterprise will embrace remanufacturing industry more positively. Meanwhile, with the growing number of companies entering into remanufacturing, the government can reduce its supervisions and save more capitals. However, remanufacturing industry in China is still at the primary stage, and it is still far away with this mature and final periods. If we expect China remanufacturing entering into this stage, the governmental supervisions at the initial stage as introduced above are necessary.

\subsection{Evolution path of remanufacturing strategies}

According to the equilibrium point obtained after solving the evolutionary game model in the previous section, and after stability analysis, the relevant ESS points can be obtained successfully. Based on this, the evolution paths between government and enterprise are shown in Fig. 3. In order to promote the better development of the remanufacturing industry, two cluster evolution paths between the government and enterprises should be proposed as follows: $\mathrm{I} \rightarrow \mathrm{III} \rightarrow \mathrm{IV} \rightarrow$ II or $\mathrm{I} \rightarrow \mathrm{IV} \rightarrow \mathrm{II}$. This industry is evolving toward to a more ecologically favorable pattern.
The evolutionary game path starts from the original point $(0,0)$ and will gradually evolve to the stable state through an unstable state. During this period, the government needs to push forward the development of remanufacturing with a "visible hand."

From the initial stage, when the total profit of remanufacturing production after receiving government subsidies is still less than the "net profit" when deducting the "penalty fees" and pollution handling expenses, the manufacturing enterprise will lose the motivation to remanufacturing. At the same time, it also means that in the initial period of the development of the remanufacturing industry, government subsidies to enterprises are not strong enough. Subsequently, by the development of industry, the government provided subsidies to the manufacturing enterprises which are engaged in remanufacturing production. And on the other hand, "levied taxes" on the companies produced pollutant emissions during their regular productions. Under the guidance of the "Subsidy-Penalty" policy, although it is able to help protect the environment and further ease the pressure on environmental protection nowadays, considering that the subsidy is far from enough and the punishment is not enough, the manufacturing companies in the remanufacturing market will still choose to conduct regular production. Remanufacturing is not their preferable strategies in this period.

With the increase in the amount of government subsidies and the growth in the taxation on pollution produced by enterprises, the expected total profit obtained by the remanufacturing production for enterprises will continue to rise. Although the profit under the regular production is still greater than the remanufacturing production at this period, some companies will start to turn their directions to remanufacturing production. At this time, the government's macro-regulatory policies begin to show the effects. The final stage is the "best ideal" stage of the evolutionary game. The government's macro-regulatory policies have achieved the desired effects. In this scenario, the expected profits obtained by the manufacturing enterprises by choosing the remanufacturing production will exceed that in regular production. Therefore, in the market, more and more manufacturing companies in China will actively choose remanufacturing production and actively abandon the original polluted production. At this time, the government does not need to increase its own serious supervision and can witness the active upgrading and transformation of manufacturing companies. From the final stage, the structure of manufacturing industry will change toward to an eco-friendly direction. 
Fig. 3 Evolutionary graph of government and enterprise

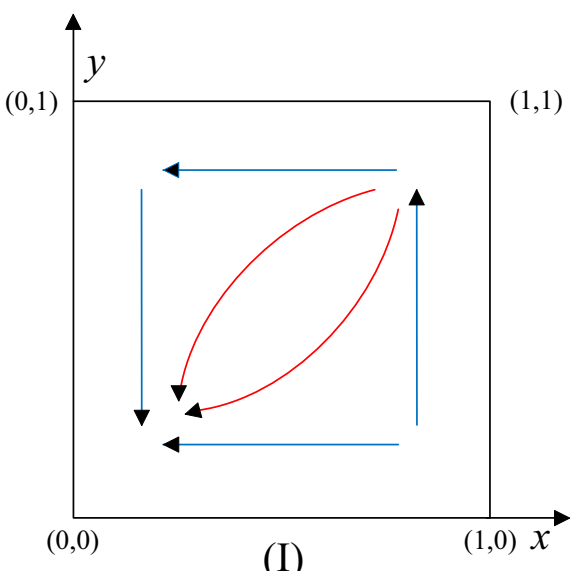

(I)

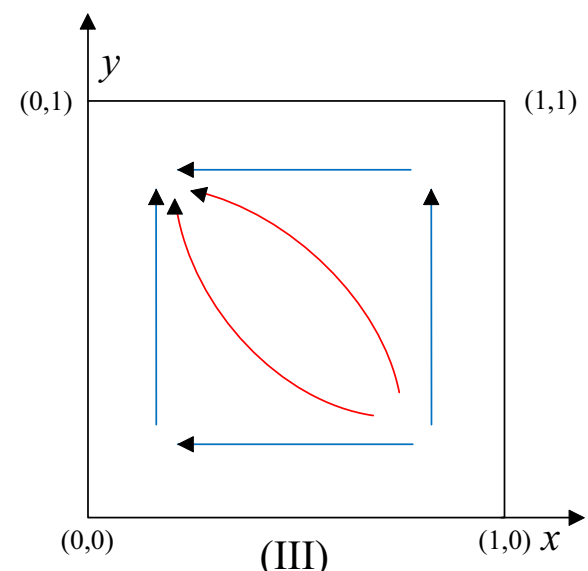

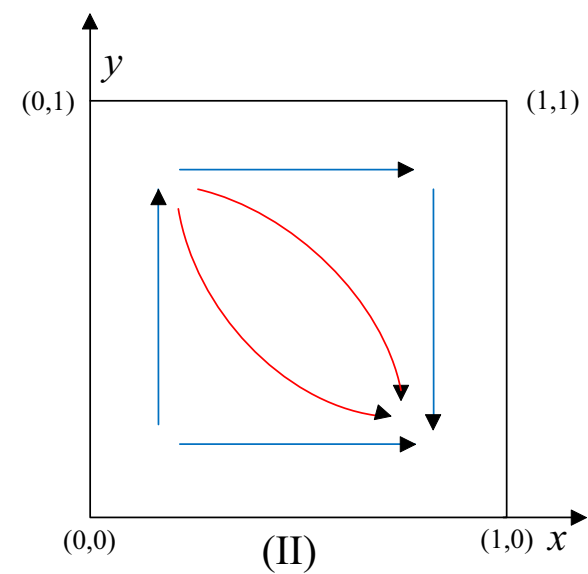

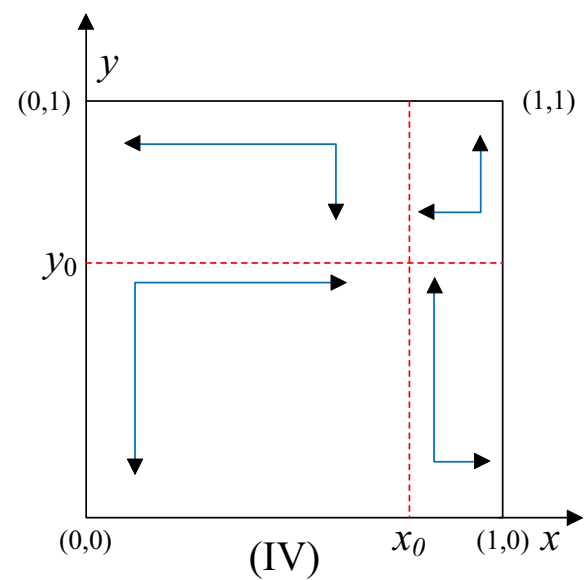

\section{Case study supporting evolutionary game model}

Since the 1990s, the number of scrapped products such as scrapped automobiles and scrapped machinery in China has shown a breakthrough growth, and how to recover a large number of scrapped products of this kind has become one of the key environmental and economic issues of the government. At the same time, a large number of smalland medium-sized enterprises have entered the manufacturing industry that was dominated by light industry and supplemented by heavy industry. At this period, the demand for raw materials such as steel and rare metals has become increasingly urgent. In order to recover a large amount of raw materials such as steel and ban illegal remanufactured products, the Chinese government promulgated the "Administrative Measures for the Recycling of Scrapped Automobiles" in June 2001, which stipulated that the five major components of scrapped automobiles must be delivered to recycling-and-dismantling sites that are qualified for the recycling and dismantling, authorized by the government.

Afterward, the metal recycling company conducts secondary processing such as metal refining. This measure has been to a large extent reduced the inflow of secondary refurbished products on the market, but also caused difficulties in recovering raw materials for the enterprises which are interested in remanufacturing. From 1990 to 2000, China's remanufacturing industry was still in the "primary" stage. Most domestic manufacturing companies such as construction machinery giants: Sany Heavy Industry, Weichai Power, China National Heavy Duty Truck, and other manufacturers, were focusing on large mass production of new products to meet the people's growing enthusiasm for production demand under the background of Reform and Opening Up. At that stage, enterprises in manufacturing industry were actively producing industrial products, driving economic growth across the country.

While considering economic gains, both enterprises and governments inevitably ignore the aspects of resource conservation and environmental protection. Generally speaking, in the "primary" stage of the development of China's remanufacturing industry, for both the government and enterprises, choosing a business model of mass production of industrial products is an ideal development strategy, and in order to consider the macro-benefits of 
rapidly driving economic growth. The government will also select a preferable strategy of "delegating powers" for some pollutant-emitting enterprises, prompting enterprises to carry out industrial production on a larger scale. Meanwhile, government in that stage, due to the backward technologies, if the government wants to supervise the pollution of enterprises, it only can require the official staff to take this task. The cost of supervision was too higher than the penalty fees gotten from the firms. Government has lack of funds to supervise polluted production positively. In this period, local governments and enterprises inevitably took the old path taken by some developed countries, such as the USA and the UK. When they quickly entered into industrialization, the phenomenon happened, "resources for economy, and environment for profits." In this stage, combining with the model, the preferable strategy set would be regarded as $(0,0)$, which means if the government does not select supervision, manufacturing companies will still select polluted production.

In the past decade or so, many cities in China have begun to be affected by smog, and the deterioration of the atmospheric environment had aroused social attention to environmental protection. How to explore China's future sustainable development has become a major new challenge to China. Since 2005, China government's penalties for polluting companies have gradually increased. Meanwhile, the environmental law enforcement agencies at all levels have concerted law enforcement efforts and have imposed a large number of rectifications and penalties on manufacturing companies that produce illegal pollutants. For example, in Liuzhou, a large industrial production city in China, 12 major polluting enterprises were banned in 2007. Several companies like Liuzhou Non-ferrous Smelting Company had been listed on the "Pollution Remediation List" three times during the 2 years and fined with huge penalty fees.

But what is thought-provoking is this type of company had been on the list three times during the 2 years, but had never carried out legal rectification. The most important internal cause is that the "destructive production" under pollution discharge has greatly reduced the production raw costs of these enterprises and brought huge economic dividends to such polluting enterprises. Therefore, in this period, most companies started from their economic point of view, in order to seek the greater "economic bonuses"; manufacturing companies would still select polluted production, even though the Chinese government published the serious regulations on industrial pollution and did extensive regulatory measures. However, in order to obtain more profits, most domestic manufacturing companies will still choose polluted production as their "preferable" production strategies. From the perspective of the evolutionary game model at this stage, the ideal strategy set will be regarded as $(1,0)$; that is, the government takes the initiatives to supervise, and the manufacturing enterprises still adopt polluted production strategy. It also means when the penalty fees were higher than supervision expenses for government, the authority would supervise the polluted production of firms more positively.

Since then, the international community's in-depth discussions on ecological, environmental, and resource issues have also prompted the Chinese government to become one of the first countries to introduce the circular economy policies and regulations at 2008 and subsequently promoted the "sustainable development" strategy in country. Some companies with advanced production concepts represented by Shanghai Caterpillar Remanufacturing Co., Ltd., have begun to try remanufacturing. The Caterpillar Remanufacturing Shanghai Plant was formally set up in December 2005. It is located in the Lingang Industrial Manufacturing Park in Shanghai, China. It was Caterpillar's first remanufacturing plant in China and a model enterprise for Sino-US remanufacturing cooperation. When the Sino-foreign joint ventures entered, they had began to attract a small number of domestic manufacturing companies to embrace remanufacturing into their new business scope.

In this period, the government's optimal decision was still maintained under the high-level supervision, and some companies with leading production concepts, such as Shanghai Caterpillar and Sany Heavy Industry, had begun to choose to enter remanufacturing activities. Noting that, owing to the core technologies they had, remanufacturing production can bring these companies more profits. So, small portion of the manufacturing firms would step into remanufacturing. But at the same time, it should be pointed out that for most manufacturing companies, their choice of polluted production could still bring the considerable economic dividends. Combined with the evolutionary game model, the decision set of $(1,1)$ is not a collection of strategies in a steady state. (A small portion of firms turned to remanufacturing, but majority of them keep regular production pattern). While the government was actively supervising the firms, there were enterprises engaged in pollutant emission. However, there were also a plenty of enterprises with the concept of "green production" which were willing to carry out remanufacturing and change their preferable decisions.

Since 2013, China's remanufacturing industry has entered into "golden period" of development. The joint launch and implementation of a series of the policies and measures were encouraging more and more companies to enter the remanufacturing industry. More than 70 companies had been selected as the pilot remanufacturing companies, which injected new vitality into this emerging industry. As a result, a new outlook for the 
remanufacturing industry was launched. It can be foreseen that in the future development of the remanufacturing industry, with the implementation of the government's remanufacturing incentive policies, the public consumers' acceptance of remanufactured products, and manufacturing companies' deepening concept on green production, a growing number of companies will begin to independently carry out remanufacturing productions and practice circular economy in their daily operations. Due to the governmental support, the revenue from remanufacturing production will increase further, which will influence the decision making of enterprises.

In the future, when the remanufacturing industry arrives to mature stage, there is no need for the government to conduct too more supervisions, and the enterprises will take the initiatives to assume the responsibility for the environmental protection and actively launch remanufacturing activities. The preferable decision of the government at that time was transformed to "decentralize power without supervision," and the preferable decision of the enterprise is seen as "actively embrace remanufacturing production." Moreover, in this period, the governmental interventions such as subsidy policy like Swap the Old for Remanufacturing can help the enterprises to reduce the production cost and make more revenues from remanufacturing. So, more and more enterprises will be willing to turn their operation directions to remanufacturing.

From the comprehensive perspective of evolutionary game model, the preferable strategy set will be seen as $(0,1)$ at the mature stage of remanufacturing industry in China. To sum up, the decision-making evolution in China remanufacturing industry is presented in Fig. 4. The

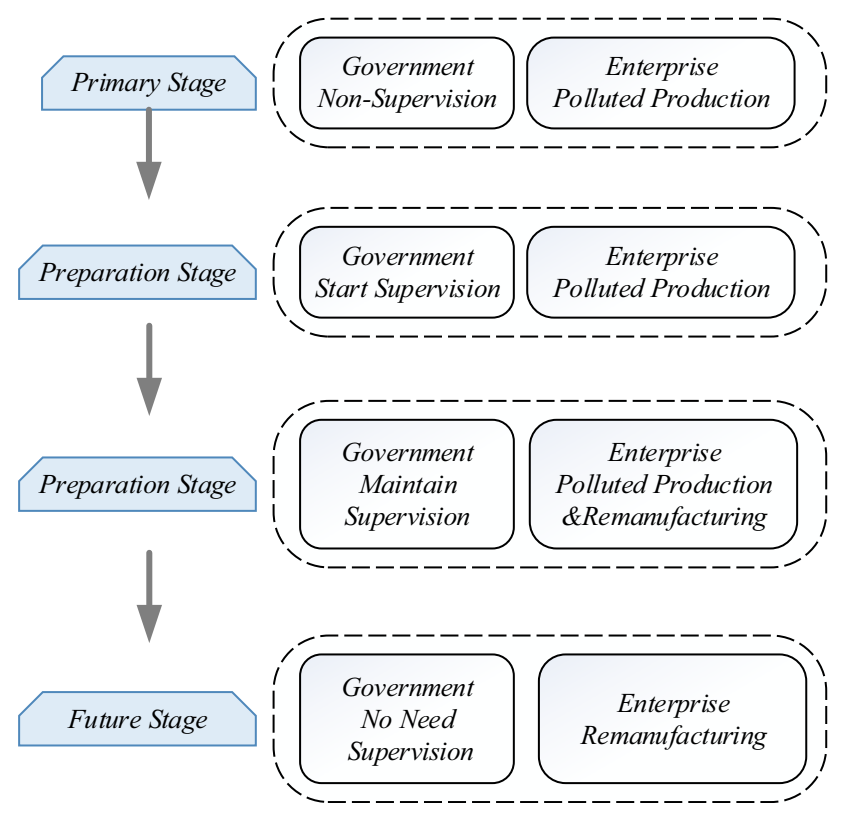

Fig. 4 Decision-making evolution in China remanufacturing industry prospects for the evolution of remanufacturing decisionmaking between government and enterprise are bright, but at the same time, it needs to be pointed out that in order to successfully evolve to this ideal stage, close cooperation between the government and enterprise is needed to interact with each other. There is still a long way to undertake before China evolves to the "ultimate" stage of the remanufacturing industry. Government and enterprises are expected to union with each other.

\section{Conclusions and practical recommendations}

This paper established an evolutionary game model of government behavior and firm's remanufacturing decision making and analyzes potential equilibrium point of evolutionary game in different situations. From the results obtained from math model, it presented clearly that when government can get the revenue which is higher than its supervision costs, government will supervise the behaviors of enterprises positively. On the contrary, government may not have the enthusiasm to take the supervisions. When it comes to the another participant in this evolutionary game model, enterprises only take remanufacturing when the profits earned via this way excel it gotten in polluted production. Otherwise, enterprises will keep polluted production though they may face the serious penalties from government. But, government can take measures like subsidy to encourage the enterprise to enter into remanufacturing. With influences of governmental regulations, a small portion of enterprises will start remanufacturing as the bellwethers at first.

Furthermore, in this research, the evolution paths between the government and enterprise have been depicted successfully. According to the paths and model analysis, we introduced a long-term perspective on the evolution of remanufacturing industry in China and further proved the rationality of the model through a case study. The practical case here describing the evolution path between China government and the enterprises proves that governmental interventions are supposed to play a crucial role to push forward the development of remanufacturing industry in China. Furthermore, the methodology "evolutionary game theory" differs from the traditional game theory, which assumed both the participants are under limited rationality. It means the parties in the game model are able to make diverse decisions during different periods of this industry. Comparing with the previous literature, evolutionary game theory makes the game model more closer to the practical operations in government and firms.

It can be seen dearly from the research results in this article that the different regulations and management methods of the government have a direct effect on the 
evolution progress of the remanufacturing industry. In different stages of industrial development in China, the government uses different regulatory methods, which play a positive role in guiding enterprises to transform and upgrade toward an eco-friendly direction in the future. Meanwhile, based on the game model above and case analysis, the following suggestions can be put forward:

- China is still in the primary stage of green industry development, and a large portion of the manufacturing enterprises have insufficient environmental awareness. Therefore, taking into account this basic domestic condition, local governments should not relax the supervision of pollution discharges and other pollution behaviors and still need to increase the penalty for pollution behaviors. Meanwhile, government is supposed to actively promote the "Environmental Tax Protection Law" and other relevant laws as well as the national regulations, and the pollution behavior shall be held accountable according to the relevant laws.

- When the government adopts penalties and other regulatory actions, it needs to accurately investigate and set different penalties according to the different pollution discharge conditions of manufacturing enterprises and must not use "one size fits all" rectification methods for all pollution discharges. For some companies that do have pollutant emissions, but respond to the related government regulations and actively adopt environmental governance, government can handle them as appropriate.

- In order to further accelerate the development of environmentally friendly industries such as the remanufacturing industry, local governments should set up the special funds and policy incentives for the enterprises engaged in remanufacturing production and adopt means such as capital subsidies and preferential taxation to help the growth of small and medium-sized remanufacturing enterprises. The government's financial subsidies will help to inject strong impetus into the green environmental protection behaviors of enterprises and lead them to remanufacturing and production.

- The environmental protection concept and the awareness of environmental responsibility of manufacturing enterprises play a key role in whether they choose remanufacturing production in their future development. Therefore, as the guider of enterprise development, the government is expected to increase the promotion and popularization to manufacturing enterprises and actively promote the dissemination of remanufacturing concepts among manufacturing enterprises in China.

Actually, this paper also have the limitations; thus, it can be extended in several aspects. For the future researches, this paper can provide several extension directions for other scholars. Firstly, we built the evolutionary game model including two participants; hence, the third participant like customers can also be taken into considerations. Then, more variables in the playoff matrix can be added such as tax discount. Thirdly, the system dynamics theory can be expected to combine with evolutionary game theory here.

Generally speaking, as an important part of the development of ecological economy and sustainable business, the remanufacturing industry has various difficulties and obstacles in its continuous development and progress. Thus, the development of the remanufacturing industry needs more positive and active guidance from the government. Only, when the remanufacturing enterprises and the government coexist with each other, they can promote the continuous progress of the remanufacturing industry successfully.

Acknowledgements This research was financially supported by the National Natural Science Foundation of China (71874159, 71371169), the National Social Science Foundation of China (18BGL184), and the Zhejiang Natural Science Foundation of China (LY18G020020). Moreover, we do appreciate all the medical personnel on the world who are fighting with the COVID-19 during this special period.

\section{Compliance with ethical standards}

Conflict of interest We declare that we do not have any commercial or associative interests that present any conflict of interest in connection with this work.

\section{References}

Afrinaldi F, Liu Z, Zhang H, Hasan A (2017) The advantages of remanufacturing from the perspective of eco-efficiency analysis: a case study. Procedia CIRP 61:223-228

Cao J, Chen X, Zhang X, Gao Y, Zhang X, Zhao Y, Kumar S (2020) Overview of remanufacturing industry in China: government policies, enterprise, and public awareness. J Clean Prod 242:118450

Chen C, Reniers G, Khakzad N (2020) Cost-benefit management of intentional domino effects in chemical industrial areas. Process Saf Environ 134:392-405

Chen W, Kucukyazici B, Verter V, Sáenz M (2015) Supply chain design for unlocking the value of remanufacturing under uncertainty. Eur J Oper Res 247(3):904-819

Chang X, Xia H, Zhu H, Fan T, Zhao H (2015) Production decisions in a hybrid manufacturing-remanufacturing system with carbon cap and trade mechanism. Int J Prod Econ 162:160-173

Chen W, Hu Z (2018) Using evolutionary game theory to study governments and manufacturers' behavioral strategies under various carbon taxes and subsidies. J Clean Prod 201:123-141

Dong H, Song H (2012) Research on duplication dynamics and evolutionary stable of reverse supply chain. Phys Procedia 24:705-709 
Gagnon RJ, Morgan SD (2014) Remanufacturing scheduling systems: an exploratory analysis comparing academic research and industry practice. Int J Rapid Manuf 4(2-4):179-198

Giovanni PD (2016) Closed-loop supply chain coordination through incentives with asymmetric information. Ann Oper Res 253:1-35

Liu Z, Jiang Q, Li T, Dong S, Yan S, Zhang H, Xu B (2016) Environmental benefits of remanufacturing: a case study of cylinder heads remanufactured through laser cladding. J Clean Prod 133:1027-1033

Ji P, Ma X, Li G (2015) Developing green purchasing relationships for the manufacturing industry: an evolutionary game theory perspective. Int J Prod Econ 166:155-162

Jin M, Nie J, Yang F, Zhou Y (2017) The impact of third-party remanufacturing on the forward supply chain: a blessing or a curse? Int J Prod Res 55(22):6871-6882

Kasman A, Duman YS (2015) CO2 emissions, economic growth, energy consumption, trade and urbanization in new EU member and candidate countries: a panel data analysis. Econ Model 44:97-103

Kelly JT, Reff A, Gantt B (2017) A method to predict PM 2.5 resulting from compliance with national ambient air quality standards. Atmos Environ 162:1-10

Krystofik M, Luccitti A, Parnell K, Thurston M (2018) Adaptive remanufacturing for multiple life cycles: a case study in office furniture. Resour Conserv Recycl 135:14-23

Maryam J, Seyyed-Mahdi H, Morteza R (2019) An evolutionary game theoretic model for analyzing pricing strategy and socially concerned behavior of manufacturers. Transp Res E Log 128:506-525

MIIT (Ministry of Industry and Information Technology) (2014) The list of pilot remanufacturing enterprises 2014. China Government, Publications. https://www.miit.gov.cn/n1146295/ n1652858/n1653100/n3767755/c4578380/part/4578384.pdf. Accessed 12 July 19

Peters K (2016) Methodological issues in life cycle assessment for remanufactured products: a critical review of existing studies and an illustrative case study. J Clean Prod 126:21-37

Rafiei R, Nourelfath M, Gaudreault J, Santa-Eulalia L, Bouchard M (2015) Dynamic safety stock in co-production demand-driven wood remanufacturing mills: a case study. Int J Prod Econ 165:90-99

Reimann M, Xiong Y, Zhou Y (2019) Managing a closed-loop supply chain with process innovation for remanufacturing. Eur J Oper Res 276:510-518

Rubio S, Corominas A (2008) Optimal manufacturing-remanufacturing policies in a lean-production environment. Comput Ind Eng 55(1):234-242

Saavedra YMB, Barquet APB, Rozenfeld H, Forcellini FA, Ometto AR (2013) Remanufacturing in Brazil: case studies on the automotive sector. J Clean Prod 94(53):267-276

Samuelson L (1997) Evolutionary games and equilibrium selection. MIT Press, Cambridge

Savaskan RC, Bhattacharya S, Van Wassenhove LN (2004) Closedloop supply chain models with product remanufacturing. Manag Sci 50:239-252

Shi J, Fan S, Wang Y, Cheng J (2019) A GHG emissions analysis method for product remanufacturing: a case study on a diesel engine. J Clean Prod 206:955-965

Smith JM (2012) Evolution and the theory of games. Cambridge University Press, Cambridge

Sofia P, George N, Christos Z, George T (2017) Joint optimization of manufacturing/remanufacturing lot sizes under imperfect information on returns quality. Eur J Oper Res 258(2):537-551

Tian J, Chen M (2014) Sustainable design for automotive products: dismantling and recycling of end-of-life vehicles. Waste Manag 34(2):458-467

Wei S, Cheng D, Sundin E, Tang O (2015) Motives and barriers of the remanufacturing industry in China. J Clean Prod 94:340-351

Wu C (2012) Price and service competition between new and remanufactured products in a two-echelon supply chain. Int $\mathbf{J}$ Prod Econ 140(1):496-507

Xiao M, Cai K, Abbass HA (2018) Hybridized encoding for evolutionary multi-objective optimization of air traffic network flow: a case study on China. Transp Res Part E Logist Transp Rev 115:35-55

Xu J, Cao J, Wang Y, Shi X, Zeng J (2020) Evolutionary game on government regulation and green supply chain decision-making. Energies 13:620 